\title{
PENGUKURAN KEDALAMAN RETAK PADA BETON KH-IPSB3 MENGGUNAKAN UPVT
}

\author{
Abdul Hafid ${ }^{1}$, Dyah Sulistyani Rahayu ${ }^{2}$ \\ ${ }^{1}$ Pusat Teknologi dan Keselamatan Reaktor Nuklir, Puspiptek, Tangerang Selatan, 15315 \\ ${ }^{2}$ Pusat Teknologi Limbah Radioaktif, Puspiptek, Tangerang Selatan, 15315 \\ Email: abdul.hafid@alumni.ui.ac.id
}

\begin{abstract}
ABSTRAK
PENGUKURAN KEDALAMAN RETAK PADA BETON KH-IPSB3 MENGGUNAKAN UPVT. Kanal Hubung Instalasi Penyimpanan Sementara Bahan Bakar Bekas (KH IPSB3) sejak awal berfungsi sebagai tempat penyimpanan bahan bakar bekas dari Reaktor RSG-GAS maupun bahan ter-iradiasi lain. Gedung KH IPSB3 terdiri atas beberapa bagian ruangan dalam bangunan antara lain ruang kontrol, ruang perlengkapan, ruang kolam, dan kolam penyimpan bahan bakar serta daerah kanal hubung. Dalam usia 24 tahun, dinding kolam dan dinding bangunan mengalami keretakan yang terlihat jelas di beberapa tempat pada saat pemeriksaan visual. Tindak lanjutnya adalah pengujian kedalaman retak menggunakan Ultrasonic Pulse Velocity Test (UPVT) berupa PUNDIT PL200. Tujuan penelitian ini adalah untuk mengukur kedalaman retak beton di lantai, dinding kanal dan dinding gedung sebagai dasar rekomendasi tindakan injeksi struktur beton. Hasil pengujian dan kajian literatur menunjukkan bahwa kedalaman selimut beton berkisar $40 \mathrm{~mm}$. Retak yang melewati tebal selimut beton dapat mengakibatkan tulangan beton memiliki potensi mudah terkorosi. Dari hasil pengujian, ditemukan kedalaman retak beton pada beberapa titik yang sudah melewati tebal selimut beton. Pada retak tersebut, segera dilakukan tindakan perawatan dan injeksi retak dengan bahan epoksi guna mencegah tulangan terkorosi.
\end{abstract}

Kata kunci: retak, kedalaman, UPVT, KH IPSB3, beton.

\section{ABSTRACT \\ MEASUREMENT OF THE CRACK DEPTH ON THE KH-IPSB3 CONCRETE USING} UPVT. The connection channels of temporary spent fuel storage installation (KH IPSB3) are designed from the beginning as a storage place for spent fuels used in the RSG-GAS Reactor and other irradiated materials. The KH IPSB3 building consists of several rooms inside the building, such as the control room, equipment room, pond, and fuel storage pool and the connecting canal area. After 24 years of operation, pond and building walls show cracks, which are clearly seen in several places during visual inspection. The follow up is by testing the depth of cracks using Ultrasonic Pulse Velocity Test (UPVT) in form of PUNDIT PL200. The purpose of this study is to measure the depth of cracks in the floors, canal and building walls as a basis for suggesting the injection of concrete structures. Test results and literature studies show that the depth of the concrete blanket is around $40 \mathrm{~mm}$ thick. Cracks passing through the thick concrete blanket can cause the reinforced concrete bars to the risk of corrosion. From the test results, the depth of the concrete cracks in the several measurement points have exceeded the thickness of the concrete blanket. For those cracks, immediate maintenance and crack injections using epoxy material have to be performed to prevent the corroding reinforcement bars.

Keywords: crack, depth, UPVT, KH IPSB3, concrete. 


\section{PENDAHULUAN}

Beton merupakan bahan yang mudah dibentuk, tahan temperatur tinggi dan memiliki kekuatan tinggi tetapi kuat tariknya rendah sehingga mudah retak. Penyebab retak pada beton dapat diakibatkan oleh pembebanan dan bisa juga karena penyusutan dari perbedaan temperature yang tinggi atau karena proses kimia antara semen dan agregat pada waktu pengerjaan.

Fasilitas KH-IPSB3 didesain sebagai tempat penyimpanan Bahan Bakar Nuklir Bekas $(\mathrm{BBNB})$ dan material ter-iradiasi tipe basah (kolam) yang dibangun pada tahun 1993[1]. Bangunan ini terbuat dari beton. Dari hasil pengamatan secara visual, pada beberapa tempat terlihat retak-retak baik pada dinding maupun pada lantai. Pada tahun 2008 ditemukan adanya rembesan di ruang purifikasi berdasarkan hasil uji tak rusak dengan metode penetran cair[2]. Tahun 2010 pemeriksaan ulang pada ruang purifikasi dilakukan dengan metode Ultrasonic Pulse Velocity Test (UPVT) diperoleh kedalaman retak beton lantai pada 3 tempat berkisar antara $55 \mathrm{~mm}$ hingga $299 \mathrm{~mm}$ selanjutnya diperbaiki dengan metode crack injection[3]. Untuk menutup retak, salah satu caranya adalah menggunakan bahan epoksi [4][5].

Uji tak rusak dengan UPVT dilakukan pada beberapa retak yang ada di lantai ruang atas kolam KH IPSB3. Tujuan penelitian ini adalah untuk mengukur kedalaman retak beton dinding dan lantai untuk dijadikan dasar rekomendasi tindakan injeksi struktur beton. Untuk dapat mencapai tujuan tersebut maka dilakukan metode pengujian tak rusak menggunakan UPVT[6] jenis PL200 dengan 2 transducer $54 \mathrm{kHz}$. Hasil pengujian dengan alat UPVT ini merupakan prediksi awal. Jika diperlukan maka pengujian lain dapat dilakukan. Analisis hasil pengujian ini dapat dijadikan data untuk mengevaluasi tingkat keamanan struktur pada KH IPSB3.

\section{TEORI}

\section{Gelombang Ultrasonik}

Gelombang frekuensi suara yang dapat didengar oleh manusia maksimal $20.000 \mathrm{~Hz}$ maka frekuensi suara lebih $20.000 \mathrm{HZ}$ merupakan ultrasonik. Cepat-lambatnya transmisi ultrasonik yang melalui material padat berhubungan dengan sifat elastisitas material [7]. Jika gelombang ultrasonik ditransmisikan ke material maka permukaan material akan bergerak ke dalam sehingga terjadi perpindahan energi. Pada material elastis menunjukkan kecenderungan untuk kembali ke posisi semula dan bergerak kearah berlawanan dengan jarak maksimum. Pada material elastis isotropik tak hingga dan homogen maka kecepatan gelombangnya dinyatakan dalam persamaan 1.

$V=\sqrt{\frac{K E_{d}}{\rho}}$

dimana: 
$V=$ kecepatan gelombang suara kompresi $(\mathrm{km} / \mathrm{det})$

$E_{d}=$ modulus elastisitas dinamis $\left(\mathrm{kN} / \mathrm{mm}^{2}\right)$

$\rho=$ densitas $\left(\mathrm{kg} / \mathrm{m}^{3}\right)$

$K=$ konstanta yang bergantung pada nilai poison rasio (v). Nilai K dirumuskan:

$$
K=\frac{(1-v)}{(1+v)(1-2 v)}
$$

Tiga jenis gelombang suara yang diterapkan pada benda padat.

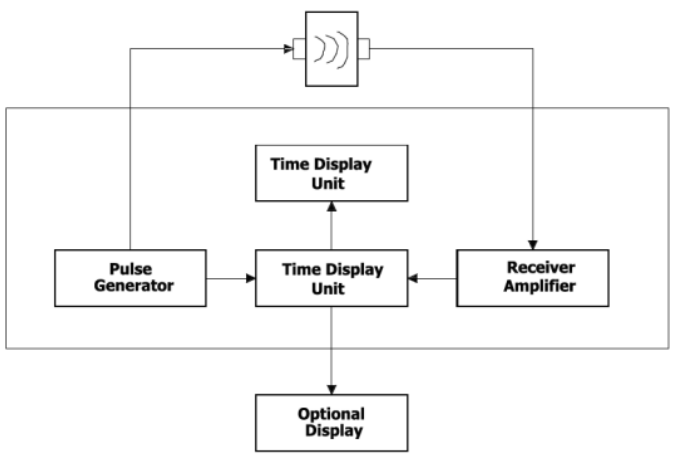

Gambar 1 Prinsip kerja alat uji UPVT[8][9].

Pengujian UPVT telah menjadi metode pengujian ultrasonik modern menggunakan frekuensi $20-150 \mathrm{kHz}$. Pengujian beton didasarkan pada kecepatan pulsa melalui transmisi teknik.

\section{Prinsip Alat uji UPVT beton}

Alat uji UPVT merupakan alat uji portable yang dapat digunakan secara langsung ditempat. Salah satu jenis alat uji UPVT adalah PUNDIT PL200 (Portable Ultrasonic Non - Destructive Digital Indicating Tester PL200). Ada tiga metode yang dapat digunakan dengan PUNDIT PL200, yaitu metode pengujian langsung (direct method), metode pengujian setengah langsung (semidirect method) dan metode pengujian tidak langsung (indirect method). Ketiga metode ini telah distandarkan berdasarkan ASTM C579, seperti ditunjukkan pada Gambar 2.

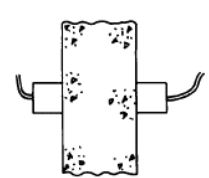

a

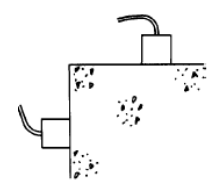

b

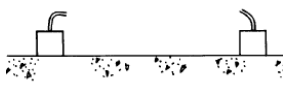

Gambar 2. Metode uji dengan PUNDIT PL200[9]

Metode pengujian langsung seperti pada Gambar 2a, posisi transducer transmitter harus berada pada posisi yang langsung berhadapan dengan transducer receiver. Transducer merupakan probe yang digunakan oleh PUNDIT PL-200 untuk meneruskan gelombang ultrasonik yang dibangkitkan (transmitter) atau dapat juga sebagai penerima gelombang ultrasonik (receiver). Pada metode pengujian semi langsung seperti Gambar 2b, posisi transmitter dan receiver saling tegak lurus. Posisi ini dilakukan apabila posisi tidak dapat dilakukan dengan metode langsung. Akurasi metode ini lebih rendah dibanding metode langsung. Metode pengujian 2c metode pengujian tidak langsung. Posisi transmitter dan receiver berada pada satu permukaan yang sama. Metode ini dilakukan karena penggunaan metode $2 \mathrm{a}$ dan $2 \mathrm{~b}$ tidak dapat dilakukan. Akurasi metode ini lebih rendah dari metode $2 b$. 
garis retak akan terjadi loncatan waktu. Cara

\section{Pengujian Kedalaman Retak}

Pengujian kedalaman retak pada beton dapat dilakukan dengan menggunakan salah satu dari tiga metode tersebut di atas. Pada makalah ini, pengujian dilakukan dengan metode tidak langsung. Pemilihan metode tidak langsung disebabkan karena posisi pengujian hanya dapat dilakukan dengan metode ini.

\section{METODOLOGI}

Pengujian kedalaman retak pada beton KH IPSB3 dilakukan dengan menggunakan alat uji UPVT yang merupakan metode uji tak rusak untuk beton menggunakan rambat gelombang suara ultrasonik. UPVT yang digunakan adalah jenis portable yaitu Portable Ultrasonic Non - Destructive Digital Indicating Tester (PUNDIT) PL200. Komponen alat terdiri dari:

a) 1 Pundit touchscreen lengkap dengan battery

b) 2 transducer $54 \mathrm{kHz}$ ( 1 transmitter dan 1 receiver)

c) 2 BNC cable $1,5 \mathrm{~m}$

d) 1 Calibration Rod

Untuk estimasi kedalaman retak dilakukan dengan indirect method. Prinsip kerjanya adalah mengukur waktu perambatan gelombang suara ultrasonic dari transmitter ke receiver pada satu bidang permukaan yang apabila gelombang suara melewati pengukuran ini ditunjukkan pada Gambar 2.

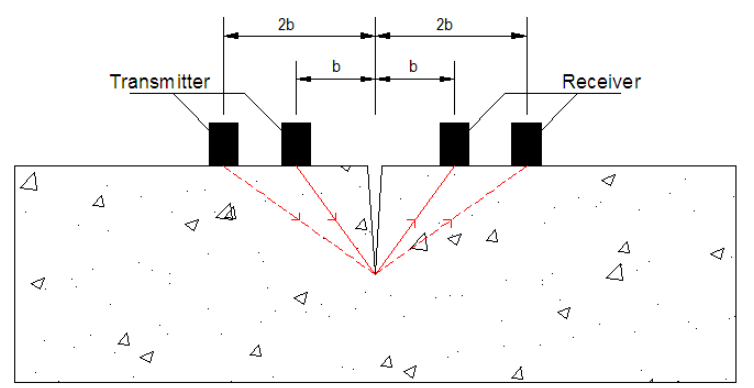

Gambar 2. Cara pengukuran kedalaman retak[7]

Mula-mula buat penandaan pada dua pasang titik yang saling berseberangan diantarai oleh keretakkan. Letakkan transmitter dan receiver pada titik pertama hingga diperoleh hasil pengukuran kemudian ulangi dengan cara yang sama pada titik yang di belakangnya. Secara teoritis nilai kedalaman retak dari dua kali pengukuran rambat gelombang dapat dihitung dengan rumus 1

$$
d=\frac{1}{2} \sqrt{\frac{X_{2}^{2} t_{1}^{2}-X_{1}^{2} t_{2}^{2}}{t_{2}^{2}-t_{1}^{2}}}
$$

dimana

$X_{1}=$ jarak antar transmitter dan receiver pada pengukuran pertama

$X_{2}=$ jarak antar transmitter dan receiver pada pengukuran kedua

$t_{1}=$ waktu yang diperlukan untuk perambatan gelombang dari transmitter ke receiver yang pertama

$t_{2}=$ waktu yang diperlukan untuk perambatan gelombang dari transmitter ke receiver yang kedua

$d=$ kedalaman retak

Pada pengukuran dengan menggunakan PUNDIT PL200, untuk pengukuran pertama 
jarak transmitter ke retak adalah sama dengan jarak reducer ke retak, misalkan jarak tersebut adalah $b$. Pada pengukuran kedua, jarak transmitter maupun reducer dibuat dua kali dari jarak yang pertama menjadi $2 b$, maka kedalaman retak dapat dihitung dengan rumus 2 .

$$
d=\frac{1}{2} \sqrt{\frac{4 t_{1}^{2}-t_{2}^{2}}{t_{2}^{2}-t_{1}^{2}}}
$$

\section{Tahapan Pengujian}

Langkah awal adalah persiapan berupa penandaan dan kalibrasi. Pilih menu kalibrasi lalu kalibrasi alat dengan menggunakan kalibrator. Setelah proses kalibrasi, pilih crack depth untuk pengujian kedalaman retak. Pengujian dilakukan dengan menempatkan transmitter dan receiver pada titik-titik yang telah ditandai. Oleskan kuplan pada permukaan transducer untuk mendapatkan hasil yang baik.

Pada makalah ini dilakukan pengujian pada 6 posisi. Letak retak ada 2 pada dinding sebelah luar kolam, disebut dinding kanal dengan penomoran 1 dan 2 seperti pada Gambar 3. Posisi lainnya pada lantai dan dinding gedung.

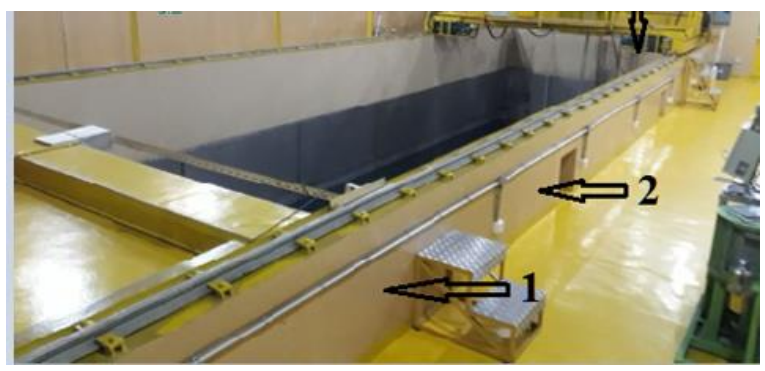

Gambar 3. Posisi retak pada dinding kolam yang diperiksa

\section{HASIL DAN PEMBAHASAN}

Retak beton bangunan KH IPSB3 terjadi pada lantai, dinding gedung dan dinding kanal. Pada penelitian ini ada 6 posisi pengambilan data, yaitu 2 pada lantai, 2 pada dinding kanal dan 2 pada dinding gedung. Pada tiap-tiap objek terdapat retak yang berbeda-beda dan terlihat secara visual seperti ditunjukkan pada Gambar 4. Pada
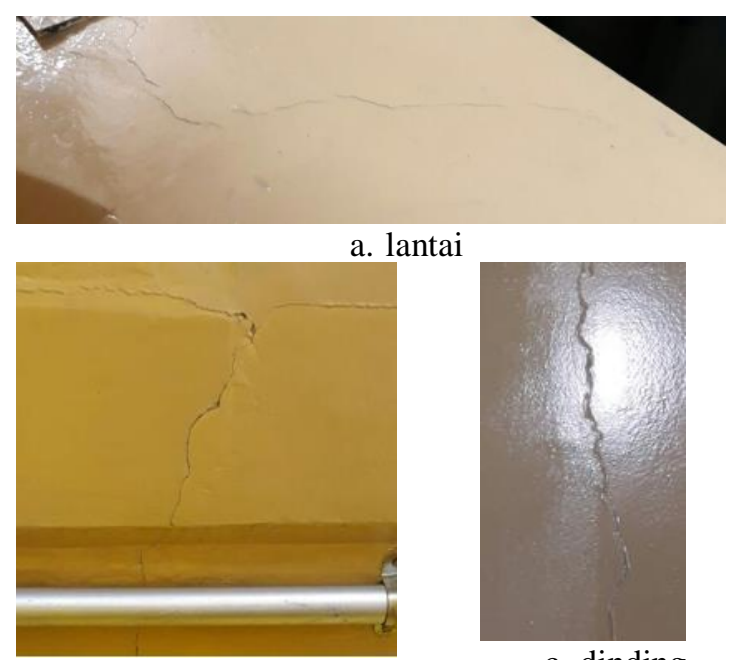

b. dinding kanal

c. dinding

Gambar 4. Retak pada lantai,dinding kanal dan dinding gedung

Pengujian kedalaman retak yang pertama dilakukan pada lantai. Untuk sampel uji maka pengujian dilakukan pada dua garis retak sperti ditunjukkan pada Tabel 1 .

Tabel 1. Kedalaman Retak Lantai KH IPSB3.

\begin{tabular}{ccc}
\hline No. & identifkasi & Kedalaman Retak $(\mathrm{mm})$ \\
\hline 1 & Lantai-1a & 65 \\
& Lantai-1b & 32 \\
& Lantai-1c & 55 \\
2 & Lantai -2a & 114 \\
& Lantai -2b & 23 \\
& Lantai -2c & 39 \\
\hline
\end{tabular}


Berdasarkan kajian literatur diperoleh bahwa akurasi pengujian dengan UPVT menggunakan metode langsung dibandingkan dengan metode tidak langsung pada beberapa material berbeda menunjukkan hasil yang berbeda-beda. Hasil penelitian Permana menyatakan bahwa salah satunya pada mortar menunjukkan nilai hingga 20,96\% dimana metode langsung lebih akurat dibanding metode tak langsung[10]. Penelitian lain oleh Jepriani menyatakan untuk metode pengujian tidak langsung, hasil pengujian dimana jarak transducer yang tetap terhadap retakkan menunjukkan bahwa pada jarak efektif tetap $30 \mathrm{~cm}$ diperoleh akurasi sebesar 15,41\% sedangkan pada jarak $15-30 \mathrm{~cm}$ nilai akurasinya16,85[11]. Jika diterapkan pada penelitian ini, hasil pengukuran mengalami koreksi sebesar 16,85\% karena jarak yang digunakan pada penelitian ini pada rentang 15-30 cm seperti pada Tabel 2.

Mengacu hasil perhitungan dan koreksinya untuk pengujian retak lantai maka untuk pengujian sampel kedalaman retak kanal dan dinding bangunan juga diterapkan sebagaimana ditunjukkan pada Tabel 3 dan 4. Berdasarkan hasil pada Tabel 2 terdapat tiga kedalaman retak yang termasuk kategori
Tabel 2. Kedalaman Retak Lantai dengan KH IPSB3.

\begin{tabular}{cccc}
\hline No. & identifkasi & $\begin{array}{l}\text { Kedalaman } \\
\text { Retak } \\
(\mathrm{mm})\end{array}$ & $\begin{array}{l}\text { Kedalaman } \\
\text { dengan Akurasi } \\
16,85 \%(\mathrm{~mm})\end{array}$ \\
\hline 1 & Lantai-1a & 65 & 54,2 \\
& Lantai-1b & 32 & 26,6 \\
& Lantai-1c & 55 & 45,7 \\
2 & Lantai -2a & 114 & 94,8 \\
& Lantai -2b & 23 & 19,1 \\
& Lantai -2c & 39 & 32,4 \\
\hline
\end{tabular}

dalam yaitu $65 \mathrm{~mm}, 55 \mathrm{~mm}$ dan $114 \mathrm{~mm}$. Apabila selimut beton memiliki ketebalan 40 $\mathrm{mm}$ maka ketiga retak tersebut telah melewati jarak selimut beton dari permukaan lantai.

Pengujian kedua dilakukan pada retak yang terjadi di dinding kanal. Untuk sampel diambil dua garis retak seperti pada Tabel 3 .

Tabel 3. Kedalaman Retak Kanal KH IPSB3 hasil pengujian dan koreksi akurasi.

\begin{tabular}{cccc}
\hline No. & identifkasi & $\begin{array}{l}\text { Kedalaman } \\
\text { Retak } \\
(\mathrm{mm})\end{array}$ & $\begin{array}{l}\text { Kedalaman } \\
\text { dengan Akurasi } \\
16,85 \%(\mathrm{~mm})\end{array}$ \\
\hline & & & \\
1 & kanal-1a & 135 & 112,3 \\
& kanal -1b & 27 & 22,5 \\
& kanal -1c & 87 & 72,3 \\
& & & 111,4 \\
2 & kanal -2a & 134 & 106,4 \\
& kanal -2b & 128 & 47,4 \\
\hline & kanal -2c & 57 & \\
\hline
\end{tabular}

Sampel retak daerah ketiga adalah retak yang terjadi pada dinding gedung seperti ditunjukkan pada Tabel 4. 
Tabel 4. Kedalaman Retak Dinding KH IPSB3 hasil pengujian dan koreksi akurasi.

\begin{tabular}{cccc}
\hline No. & identifkasi & $\begin{array}{l}\text { Kedalaman } \\
\text { Retak } \\
(\mathrm{mm})\end{array}$ & $\begin{array}{l}\text { Kedalaman } \\
\text { dengan Akurasi } \\
16,85 \%(\mathrm{~mm})\end{array}$ \\
\hline \multirow{2}{*}{1} & dindng-1a & 74 & 61,5 \\
& dindng-1b & 73 & 60,7 \\
& dindng-1c & 121 & 100,6 \\
& & & 76,5 \\
2 & dindng-2a & 92 & 115,6 \\
& dindng-2b & 139 & 81,5 \\
\hline
\end{tabular}

Pada Tabel 3 dan Tabel 4 dapat dikatakan bahwa hampir semua titik telah melewati jarak ketebalan selimut beton. Apabila retak beton mencapai atau melewati selimut beton maka ini berdampak pada kondisi tulangan beton menjadi terbuka dan mudah terserang korosi. Pada fasilitas KH IPSB3 lantai dan dinding berada di dalam ruangan tertutup dan tidak lembab. Namun demikian, kelembaban juga merupakan salah satu faktor penyebab serangan korosi jika tulangan tidak terlindungi oleh beton. Serangan korosi dapat saja terjadi pada tulangan struktur fasilitas KH IPSB3 namun berlangsung cukup lama. Berdasarkan hasil yang diperoleh dari Tabel 2, Tabel 3 dan Tabel 4 diperoleh kesimpulan bahwa retak-retak yang terjadi pada lantai, dinding kanal dan dinding gedung $\mathrm{KH}$ IPSB3 banyak yang telah melewati jarak tebal selimut beton. Oleh karena perlu dilakukan segera tindakan perbaikan, dapat berupa injeksi pada bagian yang retak atau cara lain yang dapat menutup retakan dan melindungi tulangan dari struktur bangunan.

\section{KESIMPULAN}

Retak yang terjadi pada gedung KH IPSB3 PTLR BATAN telah dilakukan pemeriksaan dengan sampel beberapa retak. Pemeriksaan menggunakan uji tak rusak dengan UPVT. Dipilih 3 tempat retak, yaitu pada lantai, dinding kanal dan dinding gedung. Dari hasil pengujian diperoleh bahwa kedalaman retak tertinggi pada dinding kanal sebesar $135 \mathrm{~mm}$ dan terendah lantai sebesar $23 \mathrm{~mm}$. Kedalaman retak yang terjadi telah mencapai bahkan melewati ketebalan selimut beton yang berfungsi sebagai pelindung baja tulangan beton terhadap kontak dengan udara terbuka guna mencegah korosi. Untuk dapat mempertahankan bangunan KH IPSB3 sebaiknya retak-retak yang terjadi dengan kedalaman yang cukup besar baik pada lantai, dinding kanal maupun dinding gedung agar dilakukan perbaikan dengan menutup retak-retak yang terjadi dengan injeksi epoksi atau bahan lain yang dapat menjaga tulagan beton dari serangan korosi.

\section{UCAPAN TERIMAKASIH}

Ucapan terima kasih disampaikan pada Kepala PTKRN dan Kepala PTLR yang telah memberi tugas untuk menganalisis gedung $\mathrm{KH}$ IPSB3 PTLR BATAN dengan dukungan dana DIPA PTKRN dan PTLR tahun 2017.

\section{DAFTAR PUSTAKA}

[1] PRSG Laporan Analisis Keselamatan kanal hubung dan Instalasi Penyimpanan sementara Bahan Bakar Bekas, PRSG-BATAN, 2002. 
[2] SULISTIYANI D., SUMARYANTO, Pendeteksian Kedalaman Retak Beton Menggunakan Metode Ultrasonik. Prosiding PPI - PDIPTN, Yogyakarta 2010, hal. $51-55$.

[3] SARAH G., HOSSEIN A., BRIAN F., Evaluation of Epoxy Injection Method for Concrete Crack Repair, International Journal of Structural and Civil Engineering Research 2017. 6(3), $177-181$.

[4] FAJAR S. H., EVIN Y. S., Analisis Injeksi Epoksi Pada Perbaikan Retak Beton Terhadap Beban Lentur, Wahana TEKNIK SIPIL 2018. 23(2), hal. $47-55$.

[5] NALINI.S, ANNAPURANI.M, SIVARANJANI S., Experimental Study On Epoxy Injection On Concrete, International Journal of Mechanical Engineering and Technology (IJMET), 2017. 8(12), pp. $227-234$.

[6] FATMA D.I., CHRISTIN R. N., MING N. W., Pengaruh Variasi Agregat Kasar Penyusun Beton Terhadap Kerapatan Beton dengan Menggunakan Transmission Time Pada Alat UPV (Ultrasonic Pulse Velocity), Rekayasa Sipil 2019, 13(1), hal. $32-39$.

[7] EUNJONG A., HYUNJUN K., SUNG-H.S., SUNG W.S., AND MYOUNGSU S., Review Principles and Applications of Ultrasonic-Based Nondestructive Methods for SelfHealing in Cementitious Materials, Materials 2017, 10(278), pp. 1 - 21

[8] FAQIH M., SLAMET W., AGUS S., Analisis Homogenitas Self Compacting Mortar Menggunakan Serta Polypropylene Berdasarkan Kecepatan Perambatan Gelombang Ultrasonik, Inersia 2011, 7(2), hal. 96 -114 .

[9] Standard Test Method for Flexural Strength of Concrete (Using Simple Beam with Third-Point Loading), ASTM C78 / C78M-16, West Conshohocken, PA, 2016

[10] PERMANA F. H., Kajian Hasil Eksperimen Penggunaan Metode Direct dan Indirect Pada Dinding Sandwich Styrofoam, Universitas Negeri Yogyakarta, 2016

[11] JEPRIANI, S, Akurasi uji ultrasonic pulse velocity (UPV) untuk mendeteksi kedalaman retak pada beton, Universitas Gajah Mada, 2008. 